\title{
Avaliação de nutrientes no solo e planta após aplicação de resíduos cianogênicos em cultura de Lactuca sativa $L$.
}

Evaluation of nutrients in soil and plants after application of cyanogenic residues in Lactuca sativa L. culture

Evaluación de nutrientes en el suelo y las plantas después de la aplicación de residuos cianogénicos en cultivo de Lactuca sativa $L$.

Edvânia Matias da Silva

Mestre, UFAL, Brasil matiasdasilva@bol.com.br

Madson Luiz Torres Santos

Mestre, UNEAL, Brasil

Madsonluiz2013@bom.com.br

Douglas Alberto de Oliveira Silva Doutor, UFPB, Brasil douglasalbertosilva@hotmail.com

Andrea Pires Fernandes Professora doutora, UFAL, Brasil fernandesdea@gmail.com

Luciana Camargo de Oliveira Professora doutora, UFSCAR, Brasil Icamargo@ufscar.br

\section{Wander Gustavo Botero}

Professor doutor, UFAL, Brasil wanderbotero@gmail.com 


\begin{abstract}
RESUMO
O processamento da mandioca para produção de farinha, gera um resíduo com elevada carga orgânica e tóxico ao ambiente devido a elevados teores de glicosídeos cianogênios, denominado manipueira. Na busca de estratégias para utilização deste resíduo como biofertilizante, diminuindo sua carga poluidora e agregando valor ao produto, este trabalho buscou avaliar a aplicação de diferentes doses de manipueira em cultura de alface (Lactuca sativa L.), avaliando o crescimento das plantas, os teores de nutrientes absorvidos pelas plantas e o impacto dessa aplicação nas características do solo. Os resultados evidenciaram que a dose $6,6 \mathrm{~m}^{3} \mathrm{ha}^{-1}$ propiciou maior incremento de massa fresca e massa seca da parte aérea, enquanto a dose $26,4 \mathrm{~m}^{3}$ ha-1 proporcionou incremento significativo nos demais parâmetros fisiológicos avaliados. Doses de manipueira superiores a esse valor apresentaram efeito deletério e ocasionaram o decréscimo em todos os parâmetros de crescimento analisados. A utilização de doses crescentes de manipueira propiciou acúmulos de nutrientes na parte aérea da alface, na seguinte ordem: $\mathrm{Fe}>\mathrm{Mg}>\mathrm{Mn}>\mathrm{Z}>\mathrm{Ca}>\mathrm{Cu}>\mathrm{P}>\mathrm{K}$, não apresentando deficiência de nutrientes. A incorporação da manipueira nos solos promoveu elevação do $\mathrm{pH}$, da matéria orgânica e dos teores de fósforo, potássio, magnésio e sódio trocáveis e baixo incremento de CTC e Ca. Assim, o uso da manipueira como biofertilizante se mostrou adequado e promissor, aumentando os teores de nutrientes na planta e solo após aplicação, indicando sua possível utilização como complemento no cultivo de hortaliças.
\end{abstract}

PALAVRAS-CHAVE: Fertilizante. Solos. Manipueira.

\begin{abstract}
The processing of cassava to produce flour generates a residue with a high organic load and toxic to the environment due to high levels of cyanogenic glycosides, called "manipueira". In the search for strategies for using this residue as a biofertilizer, reducing its polluting load and adding value to the product, this work sought to evaluate the application of different doses of manipueira in lettuce (Lactuca sativa L.), evaluating the growth of plants, nutrient content absorbed by plants and the impact of this application on soil characteristics. The results showed that the $6.6 \mathrm{~m}^{3} \mathrm{ha}^{-1}$ dose provided a greater increase in fresh and dry mass of the aerial part, while the $26.4 \mathrm{~m}^{3} \mathrm{ha}^{-1}$ dose provided a significant increase in the other physiological parameters evaluated. Doses of manipueira higher than this value had a deleterious effect and caused a decrease in all growth parameters analyzed. The use of increasing doses of manipueira led to accumulation of nutrients in the aerial part of the lettuce, in the following order: Fe $>M g>M n>Z>$ $\mathrm{Ca}>\mathrm{Cu}>\mathrm{P}>K$, with no nutrient deficiency. The incorporation of manipueira in the soils promoted an increase in $p H$, organic matter and the levels of exchangeable phosphorus, potassium, magnesium and sodium and a low increase in CTC and Ca. Thus, the use of manipueira as a biofertilizer proved to be adequate and promising, increasing nutrient content in the plant and soil after application, indicating its possible use as a complement in the cultivation of vegetables.
\end{abstract}

KEYWORDS: Fertilizer. Soils. Manipueira.

\title{
RESUMEN
}

El procesamiento de la yuca para producir harina genera un residuo con una alta carga orgánica y tóxico para el medio ambiente debido a los altos niveles de glucósidos cianogénicos, llamados "manipueira". En la búsqueda de estrategias para usar este residuo como biofertilizante, reduciendo su carga contaminante y agregando valor al producto, este trabajo buscó evaluar la aplicación de diferentes dosis de manipueira en lechuga (Lactuca sativa L.), evaluando el crecimiento de las plantas, contenido de nutrientes absorbidos por las plantas y el impacto de esta aplicación en las características del suelo. Los resultados mostraron que la dosis de $6.6 \mathrm{~m}^{3} \mathrm{ha}^{-1}$ proporcionó un mayor aumento en el peso fresco y la masa seca de la parte aérea, mientras que la dosis de $26.4 \mathrm{~m}^{3} \mathrm{ha}^{-1}$ proporcionó un aumento significativo en los otros parámetros fisiológicos evaluados. Las dosis de manipueira superiores a este valor tuvieron un efecto nocivo y causaron una disminución en todos los parámetros de crecimiento analizados. El uso de dosis crecientes de manipueira condujo a la acumulación de nutrientes en la parte aérea de la lechuga, en el siguiente orden: $\mathrm{Fe}>\mathrm{Mg}>\mathrm{Mn}>\mathrm{Z}>\mathrm{Ca}>\mathrm{Cu}>\mathrm{P}>K$, sin deficiencia de nutrientes. La incorporación de manipueira en los suelos promovió un aumento en el $\mathrm{pH}$, la materia orgánica y los niveles de fósforo, potasio, magnesio y sodio intercambiables y un bajo aumento en CTC y Ca. Por lo tanto, el uso de manipueira como biofertilizante demostró ser adecuado y prometedor, aumentando contenido de nutrientes en la planta y el suelo después de la aplicación, lo que indica su posible uso como complemento en el cultivo de hortalizas.

PALABRAS CLAVE: Fertilizante. Suelos. Manipueira 


\section{INTRODUÇÃO}

Do beneficiamento das raízes de mandioca para fabricação de farinha de mesa e fécula, são gerados resíduos líquidos advindos de atividades agroindustriais, constituídos da água de lavagem das raízes e da água de prensagem da mandioca, comumente denominada manipueira (INOUE et al., 2001; SOUZA et al.,2014).

Essa água de prensagem das raízes de mandioca (manipueira) contém açúcares, amidos, proteínas, linamarina, sais e outras substâncias (DUARTE et al., 2012). Sua composição química sustenta a sua potencialidade como nutriente, por apresentar elevados teores de potássio, magnésio, fósforo, cálcio, enxofre, ferro e micronutrientes em geral. Entretanto, apresenta elevados teores de cianeto, o que a torna um resíduo perigoso e altamente tóxico (SOUZA et al., 2014).

O reuso de efluentes e resíduos advindos de atividades agroindustriais vem sendo encorajado como forma de diminuir a poluição ambiental causada pelo descarte indiscriminado e, entre as medidas propostas para o gerenciamento adequado de tais efluentes e resíduos, está a sua reutilização em substituição à adubação mineral na produção agrícola (DAMASCENO, 2003). 0 seu reaproveitamento para a fertilização, no entanto, é uma alternativa eficaz para sanar o despejo incorreto e ainda, contribuir com nutrientes para a produtividade das plantas.

A manipueira, além de apresentar vantagens econômicas por ser um material disponível e de baixo custo em regiões do nordeste brasileiro, pode substituir adubos industrializados. Mudas de eucalipto obtiveram máximos valores de crescimento e desenvolvimento, quando foram irrigadas com manipueira. (SALVADOR et al., 2012).

A literatura relata sobre a aplicação de doses crescentes de manipueira, via foliar, no desenvolvimento do milho, constatando eficácia para doses de $75 \%$ (750 ml de manipueira $+250 \mathrm{ml}$ de água) garantindo incrementos significativos de massa fresca, altura de planta e número de folhas (ARAÚJO et al., 2004).

Embora a cultura da alface siga o mesmo padrão de desenvolvimento, fatores como cultivares diferentes, solo, adubação, clima, práticas culturais, moléstias e época de plantio são capazes de interferir no número total de folhas desenvolvidas, e na qualidade da alface (ZIECH et al., 2014).

Tendo em vista os riscos que o descarte indiscriminado dos resíduos agroindustriais pode trazer ao ambiente, em especial resíduos cianogênicos e por apresentarem teores consideráveis de nutrientes, este trabalho teve por objetivo avaliar efeito ocasionado pela aplicação de doses crescentes de manipueira no desenvolvimento da alface (Lactuca sativa L.)e no solo, após prétratamento buscando minimizar os teores de glicosídeos cianogenicos neste resíduo.

\section{METODOLOGIA}

\subsection{Instalação e condução dos experimentos}

O experimento foi realizado em casa de vegetação. Os solos utilizados foram coletados no município de Arapiraca, Alagoas na profundidade $0-20 \mathrm{~cm}$ e caracterizado como argisolo vermelho com análise de fertilidade realizada pelo Laboratório de fertilidade do Solo Departamento de recursos Ambientais da Faculdade de ciências Agronômicas/ UNESP, Botucatu - SP: $\mathrm{pH}=6,3 ; \mathrm{MO}=18 \mathrm{~g} / \mathrm{dm}^{3} ; \mathrm{K}=0,3 \mathrm{cmolc} / \mathrm{dm}^{3} ; \mathrm{F}=36 \mathrm{mg} / \mathrm{dm}^{3} ; \mathrm{Ca}=4,4 \mathrm{cmolc} / \mathrm{dm}^{3} ; \mathrm{Na}=0,1$ $\mathrm{mmolc} / \mathrm{dm}^{3} ; \mathrm{Mg}=16 \mathrm{mmolc} / \mathrm{dm}^{3} ; \mathrm{Fe}=17 \mathrm{mg} / \mathrm{dm}^{3}$ e $\mathrm{Mn}=4,7 \mathrm{mg} / \mathrm{dm}^{3}$. 
Para a realização do experimento foram utilizados vasos com capacidade de $4 \mathrm{~L}$ contendo $500 \mathrm{~g}$ de brita número 0 , manta bidim com peso de $10 \mathrm{~g}$ e $4,800 \mathrm{~kg}$ de material de solo utilizado para o cultivo. Após a montagem, três vasos foram saturados por capilaridade e pesados diariamente, até se obter peso constante, ou seja, quando o solo se encontrava em capacidade de campo. Mudas de Lactuca sativa L. (alface) foram transplantadas para os vasos após apresentarem seis folhas definitivas e 5 dias após aplicação da manipueira no solo. A cultura de alface apresenta ciclo de 30 a 35 dias após o transplante de mudas. Para o controle de plantas invasoras durante o experimento foram adotadas as recomendações técnicas para a cultura da alface, sendo este realizado semanalmente, pelo método manual (RESENDE et al., 2009).

\subsection{Manipueira}

A manipueira foi coletada em uma casa de farinha localizada no município de Arapiraca-AL. Os macros e micronutrientes foram determinados por espectrometria de absorção atômica (AAS), utilizando-se soluções padrão mista para curva de calibração. Conforme a metodologia específica baseada no Standart Methods conforme Charriau et al., (2005). Antes da aplicação de manipueira no solo para avaliação do desenvolvimento de alface, a manipueira foi armazenada em recipiente plástico aberto por 5 dias ao sol conforme metodologia recomendada por Souza et al (2014). Trabalhos prévios do grupo de pesquisa e publicados por Souza et al (2014), mostram que a perda de cianeto livre nas amostras de manipueira se dá de forma rápida nas primeiras 24 horas de exposição ao sol. Após 5 dias, cerca de $80 \%$ do ácido cianídrico é liberado e o resíduo apresenta níveis adequados e dentro do permitido pela legislação brasileira para utilização em setores agrícolas.

\subsection{Delineamento experimental}

O delineamento experimental foi inteiramente casualizado em esquema fatorial $5 \times 3$; com quatro repetições, totalizando 60 parcelas experimentais. Os fatores de estudo da pesquisa foram: doses de manipueira $0 ; 6,6 ; 13,2 ; 26,4 ; 52,8 \mathrm{~m}^{3} \mathrm{ha}^{-1}$ e tempos de incubação aos 10 , 20 e 30 dias após o transplante da alface (DAT). As doses de manipueira foram determinadas levando-se em consideração a concentração de potássio nela existente e no solo, bem como a exigência desse nutriente pela cultura da alface, de acordo com a recomendação proposta por IPA (2008). Nesse experimento não foi realizado calagem do solo e adubação mineral com o intuito de avaliar apenas o efeito que o uso da manipueira exerceu sobre a cultura e o solo.

\subsection{Parâmetros de crescimento}

Aos 10, 20 e 30 DAT, as plantas foram colhidas e encaminhadas ao Laboratório de Ciências Ambientais do Agreste da Universidade Federal de Alagoas para determinação da massa fresca das folhas. A massa seca das folhas (MSF) foi determinada segundo metodologia proposta por Benincasa (2003) que consiste na secagem das folhas em estufa com circulação forçada de ar a $65^{\circ} \mathrm{C}$ até massa constante. Para acompanhar o desenvolvimento das plantas foram monitorados os seguintes parâmetros: altura de plantas (AP), área foliar $(\mathrm{AF})$, diâmetro de caule (DC), número de folhas (NF), massa seca da parte aérea (MSPA) e massa fresca da parte aérea (MFPA) com leituras realizadas a cada dez dias após a germinação.

Os dados obtidos foram submetidos à análise de variância e regressão utilizando o software estatístico SISVAR, com níveis de significância de $5 \%$ para o teste $\mathrm{F}$. Alguns parâmetros não 
apresentaram modelos ajustáveis para regressão (linear e quadrática), sendo utilizado o teste de Tukey ao nível de $5 \%$ de probabilidade.

\subsection{Determinações de macro e micronutrientes das plantas e análise de fertilidade nos solos}

Após o ciclo de cultivo ( 30 dias) as amostras de alface foram trituradas em moinho de facas tipo Willey e digeridas com ácido nítrico para determinação de macro e micronutrientes ( $N$, $\mathrm{P}, \mathrm{K}, \mathrm{Ca}, \mathrm{Mg}, \mathrm{Fe}, \mathrm{Zn}, \mathrm{Cu}$ e Mn) (NEVES et al., 2016).

Os macros e micronutrientes foram determinados por espectrometria de absorção atômica (AAS), utilizando-se soluções padrão mista para curva de calibração. Conforme a metodologia específica baseada no Standart Methods conforme Charriau et al., (2005).

Para avaliar os efeitos da adição da manipueira nas características do solo, os parâmetros químicos do solo foram analisados antes da aplicação da manipueira no solo, e após 10 e 30 dias da aplicação da manipueira.

Os dados obtidos foram submetidos à análise de variância e regressão utilizando o software estatístico SISVAR, com níveis de significância de 5\% para o teste $\mathrm{F}$. Alguns parâmetros não apresentaram modelos ajustáveis para regressão (linear e quadrática), sendo utilizado o teste de Tukey ao nível de $5 \%$ de probabilidade.

\section{RESULTADOS}

A manipueira aplicada neste experimento seguiu as recomendações sugeridas por Souza et al. (2014), que avaliou maneiras de minimizar os teores de compostos cianogênicos da manipueira de forma simples, rápida e barata. Assim, após a exposição da manipueira por $24 \mathrm{~h}$ em sol e recipiente aberto, o teor de íons cianeto foi de $1,5 \mathrm{mg} \mathrm{L}^{-1}$. Os teores de nutrientes na amostra de manipueira determinado foi: $\mathrm{Cu}: 0,58 \pm 0,01$; Fe: $21,96 \pm 0,04 ; \mathrm{Zn}: 4,91 \pm 0,02 ; \mathrm{Mn}: 2,18 \pm 0,03$;

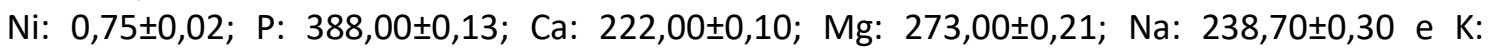
$709,16 \pm 0,22 \mathrm{mg} \mathrm{L}^{-1}$.

\subsection{Avaliação da aplicação de manipueira em alface: parâmetros de crescimento}

Os parâmetros altura de plantas (AP), área foliar (AF), diâmetro de caule (DC), número de folhas (NF), massa seca da parte aérea (MSPA) e massa fresca da parte aérea (MFPA) com determinações realizadas a cada dez dias após a germinação estão listadas na Tabela 1. 
Tabela 1. Resumo da Análise de variância de regressão para as variáveis área foliar, massa fresca da parte aérea, diâmetro do caule, altura da planta, matéria seca da parte aérea e número de folhas da cultura da alface submetidas a diferentes doses de manipueira aos 10, 20 e 30 dias após o transplante

\begin{tabular}{|c|c|c|c|c|}
\hline \multicolumn{5}{|c|}{ Quadrado Médio - Dias após o transplante } \\
\hline Fonte de Variação & GL & 10 & 20 & 30 \\
\hline \multicolumn{5}{|c|}{ Área Foliar } \\
\hline Regressão Linear & 1 & $0,91^{\mathrm{ns}}$ & $6,59^{\text {ns }}$ & $862,73^{* *}$ \\
\hline Regressão Quadrática & 1 & $8,01^{\text {ns }}$ & $170,59^{* *}$ & $1998,17^{* *}$ \\
\hline Resíduo & 45 & 4,6 & 4,6 & 4,6 \\
\hline \multicolumn{5}{|c|}{ Massa Fresca da parte aérea } \\
\hline Regressão Linear & 1 & $17,28^{\text {ns }}$ & $87,95^{\text {ns }}$ & $4048,15^{* *}$ \\
\hline Regressão Quadrática & 1 & $43,12^{\text {ns }}$ & $30,30^{* *}$ & $50935,76^{* *}$ \\
\hline Resíduo & 45 & 63,24 & 63,24 & 63,24 \\
\hline \multicolumn{5}{|c|}{ Diâmetro do caule } \\
\hline Regressão Linear & 1 & $6,64^{\text {ns }}$ & $7,69^{*}$ & $9,33^{*}$ \\
\hline Regressão Quadrática & 1 & $0,01^{\text {ns }}$ & $47,47^{* *}$ & $58,98^{* *}$ \\
\hline Resíduo & 45 & 1,45 & 1,45 & 1,45 \\
\hline \multicolumn{5}{|c|}{ Altura da Planta } \\
\hline Regressão Linear & 1 & $1,63^{\text {ns }}$ & $6,78^{*}$ & $195,80^{* *}$ \\
\hline Regressão Quadrática & 1 & $7,12^{\mathrm{ns}}$ & $250,17^{* *}$ & $714,22 * *$ \\
\hline Resíduo & 45 & 1,57 & 1,57 & 1,57 \\
\hline \multicolumn{5}{|c|}{ Matéria Seca da Parte aérea } \\
\hline Regressão Linear & 1 & $0,07^{n s}$ & $0,52^{\text {ns }}$ & $39,27 * *$ \\
\hline Regressão Quadrática & 1 & $0,18^{\text {ns }}$ & $16,41 * *$ & $399,78^{* *}$ \\
\hline Resíduo & 45 & 0,73 & 0,73 & 0,73 \\
\hline \multicolumn{5}{|c|}{ Número de folhas } \\
\hline Regressão Linear & 1 & $3,18^{\text {ns }}$ & $8,9^{\text {ns }}$ & $202,8^{* *}$ \\
\hline Regressão Quadrática & 1 & $11,09^{n s}$ & $229,3^{* *}$ & $973,3^{* *}$ \\
\hline Resíduo & 45 & 3,2 & 3,2 & 3,2 \\
\hline
\end{tabular}

* e **Significativos a 0,05 e 0,01 de probabilidade, respectivamente, pelo teste $\mathrm{F}$

Ns não significativo pelo teste $\mathrm{F}$.

Médias seguidas das mesmas letras na coluna não diferem entre si a 5\% e 1\% de probabilidade, pelo teste Tukey.

Fonte: Dados da pesquisa, 2016.

O aumento das doses da manipueira promoveu efeito quadrático (Figuras 1 A, B, C) na área foliar, diâmetro do caule e número de folhas em todas as épocas avaliadas. 
Figura 1. Área foliar (A), diâmetro do caule (B) e número de folhas (C) da alface em função das doses de manipueira aplicadas.
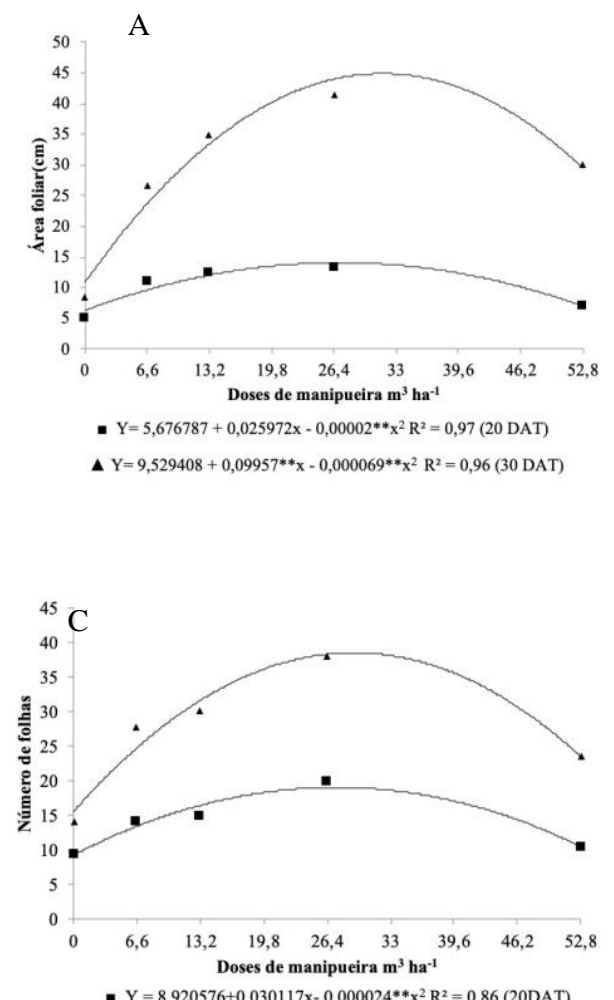

$Y=8,920576+0,030117 x-0,000024 * * x^{2} R^{2}=0,86(20 D A T)$

$\Delta \mathrm{Y}=14,562367+0,066246^{* *} \mathrm{x}-0,000048^{* *} \mathrm{x}^{2} \mathrm{R}^{2}=0,94(30 \mathrm{DAT})$

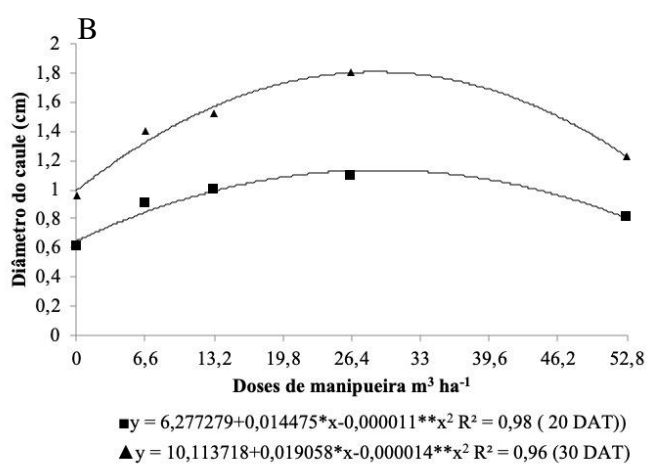

$\Delta \mathrm{y}=10,113718+0,019058^{*} \mathrm{x}-0,000014^{* *} \mathrm{x}^{2} \mathrm{R}^{2}=0,96(30 \mathrm{DAT})$

Verificou-se que as plantas cultivadas no solo que recebeu a dose de manipueira correspondente a $26,4 \mathrm{~m}^{3} \mathrm{ha}^{-1}$ apresentaram melhor desenvolvimento em todos os parâmetros de crescimento analisados neste estudo aos 20 DAT e 30 DAT.

De acordo com Severiano et al. (2004), a área foliar reflete na capacidade fotossintética dos vegetais e está relacionada com a cobertura do solo e com a capacidade de competição entre as plantas em uma mesma área. Doses acima de $26,4 \mathrm{~m}^{3} \mathrm{ha}^{-1}$ de manipueira interferiram de modo negativo na expansão da área foliar da alface. Isso se deu provavelmente em função de algum efeito deletério de potássio em excesso no solo, impedindo a absorção de outros nutrientes pela planta. Estudando os efeitos de doses crescentes de potássio na cultura da alface Souza e colaboradores (2007) verificou o decréscimo de área foliar quando este nutriente foi aplicado na dose $200 \mathrm{~kg} \mathrm{ha}^{-1}$.

No período de 20 DAT (Figura 1), as plantas absorvem do solo os nutrientes para o seu desenvolvimento, e aos 30 DAT ocorre o crescimento significativo do caule em diâmetro, apresentado o maior valor 1,1 e $1,8 \mathrm{~cm}$ na dose $26,3 \mathrm{~m}^{3} \mathrm{ha}^{-1}$ aos 20 e 30 DAT respectivamente, se comparado com a testemunha. Segundo Magalhães (2014), o caule armazena os nutrientes, que disponibiliza para a formação das folhas.

O número de folhas (Figuras $2 \mathrm{~A}, \mathrm{~B}, \mathrm{C}$ ), obteve um comportamento quadrático com o aumento dos valores em função do aumento das doses do resíduo nas épocas avaliadas apresentado 20 e 38 folhas na dose $26,4 \mathrm{~m}^{3} \mathrm{ha}^{-1}$ aos 20 DAT e 30 DAT respectivamente. 
Figura 2. Massa fresca da parte aérea (A), massa seca da parte aérea (B) da alface e altura da planta (C) em função das doses de manipueira aplicadas.
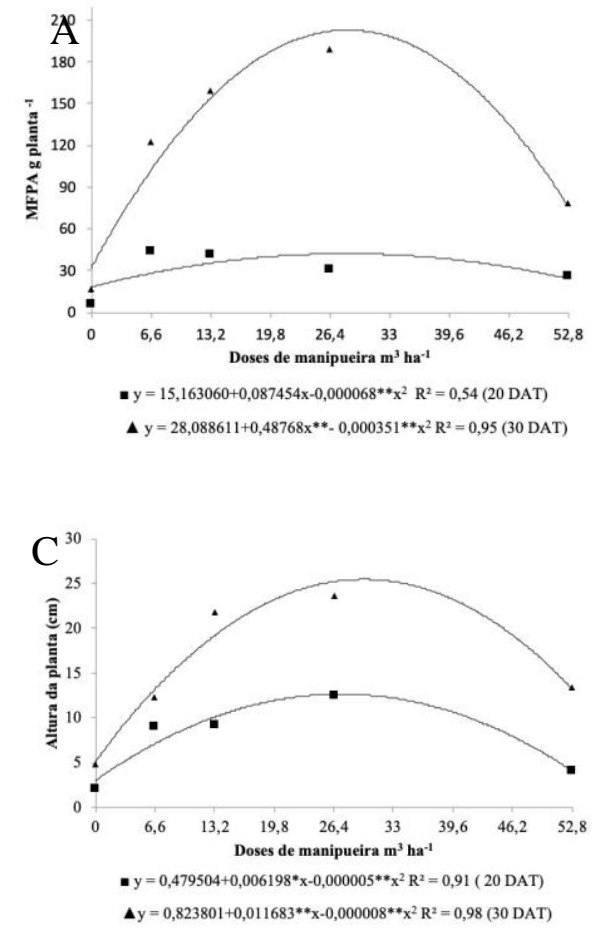

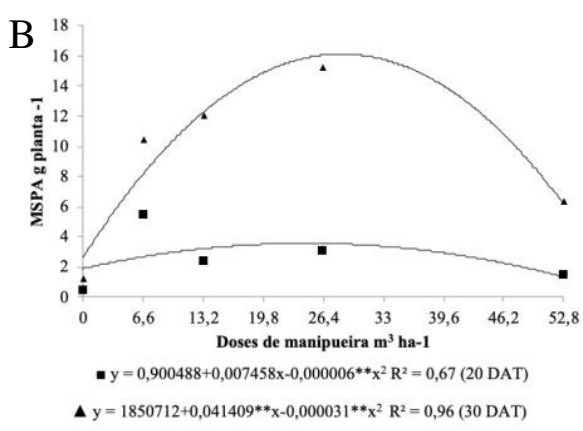

$\mathrm{y}=1850712+0,041409^{* *} \mathrm{x}-0,000031^{* *} \mathrm{x}^{2} \mathrm{R}^{2}=0,96(30 \mathrm{DAT})$

Os resultados evidenciam respostas positivas no uso de manipueira como fonte de nutrientes, entretanto, doses acima de $26,4 \mathrm{~m}^{3} \mathrm{ha}^{-1}$ acarretam um decréscimo no número de folhas, área foliar, diâmetro do caule e altura da planta evidenciando que possivelmente, tenha ocorrido efeito antagônico de algum nutriente contido no resíduo utilizado.

Corroborando os dados obtidos neste trabalho, Salvador et al (2012), utilizando manipueira como fonte de fertilizante para a produção de mudas de eucalipto, verificou que o crescimento das plantas foi influenciado com o aumento das doses do efluente de fecularia.

Aos 30 DAT a equação de regressão obtida para a massa fresca das plantas foi quadrática com o valor máximo de 189,0 g planta ${ }^{-1}$. Já para a massa seca, o valor obtido foi de $15,2 \mathrm{~g} \mathrm{planta}^{-1}$ correspondendo a dose $26,4 \mathrm{~m}^{3} \mathrm{ha}^{-1}$. No entanto, doses acima de $26,4 \mathrm{~m}^{3} \mathrm{ha}^{-1}$ ocasionaram decréscimo nas variáveis em análise, possivelmente devido a planta ter atingido o tamanho definitivo.

Em consonância com os dados obtidos neste estudo, Cardoso et al. (2005) afirmam que o milho cultivado em área biofertilizada com a manipueira apresentou maior massa seca e massa fresca da parte área de cultivo e consequentemente maior produtividade do que o milho cultivado em solo adubado com fertilizante mineral, sendo este aumento creditado devido a manipueira ser rica principalmente em potássio e nitrogênio.

Silva et al. (2004) concluíram que a quantidade de massa seca da alface aumentou em função do uso de fertilizante nitrogenado e fosfatado aliado ao uso de esterco bovino, sendo conseguido teor de matéria seca das folhas igual a 102,7 $\mathrm{g} \mathrm{planta}^{-1}$.

Segundo Zobiole et al. (2010), a altura da planta apresenta herança genética quantitativa sendo encontrado predomínio de efeitos gênicos aditivos e o de efeitos gênicos não aditivos na determinação desta característica fenológica. 
Os dados obtidos neste trabalho mostram que as plantas submetidas a doses crescentes de manipueira se desenvolvem melhor, uma vez que todos os parâmetros de crescimento estudados foram significativamente maiores do que o das plantas que não receberam o resíduo e evidencia, portanto, que este resíduo quando tratado pode ser aproveitado na produção agrícola por possuir nutrientes. No entanto, os resultados destacam que a manipueira deve ser utilizada em doses adequadas, ou poderá causar danos as culturas, já que o excesso de nutrientes no solo, sobretudo potássio, nitrogênio e sódio poderá provocar desequilíbrio nutricional nas plantas, (Melo et al., 2009 e Duarte et al., 2012).

\subsection{Teores de nutrientes absorvidos em alface após aplicação de manipueira.}

As análises de variância dos dados mostraram que as variáveis analisadas sofreram efeito com aumento das doses de manipueira.

Tabela 2. Valores médios e significância do teste $F$ para teores de macro e micronutrientes nas folhas de alface, em função das doses de manipueira

\begin{tabular}{|c|c|c|c|c|c|c|c|c|c|}
\hline \multicolumn{10}{|c|}{ Teores } \\
\hline $\begin{array}{c}\text { Doses de } \\
\text { manipueira } \\
\left(\mathrm{m}^{3} \mathrm{ha}^{-1}\right)\end{array}$ & $\mathbf{N}$ & $\begin{array}{l}\text { P } \\
-g\end{array}$ & K & $\mathrm{Ca}$ & Mg & $\mathrm{Fe}$ & $\begin{array}{c}\mathrm{Zn} \\
-\mathrm{mg} \mathrm{Kg}\end{array}$ & $\mathrm{Cu}$ & Mn \\
\hline 0 & $26,9 d$ & $2,5 a$ & $26,1 \mathrm{a}$ & $10,5 b$ & $3,3 c$ & $35,7 d$ & $15,4 c$ & $5,6 d$ & $22,36 \mathrm{e}$ \\
\hline 6,6 & $29,2 c$ & $2,1 b$ & $29,3 \mathrm{a}$ & $12,5 b$ & $5,5 b c$ & $55,9 c$ & $18,16 \mathrm{c}$ & $6,6 \mathrm{a}$ & $40,96 b$ \\
\hline 13,2 & $40,8 b$ & $2,3 b$ & $29,7 \mathrm{a}$ & $13,3 b$ & $6,3 a b$ & $105,9 a$ & $22,72 \mathrm{c}$ & $3,4 b$ & $36,77 c$ \\
\hline 26,4 & $42,2 b$ & $3,4 \mathrm{a}$ & 29,9 a & $13,0 \mathrm{ab}$ & $5,9 a b$ & $85,6 b$ & $16,55 b$ & 8,6 a & $26,99 d$ \\
\hline 52,8 & 44,9 a & $3,8 \mathrm{a}$ & $31,5 \mathrm{a}$ & 16,9 a & $7,8 a$ & $55,6 c$ & $27,66 a$ & 9,0 a & $45,55 \mathrm{a}$ \\
\hline Teste F & $\mathrm{Q}^{* *}$ & $\mathrm{Q}^{*}$ & ns & $\mathrm{L}^{* *}$ & $\mathrm{~L}^{*}$ & $\mathrm{Q}^{* *}$ & $\mathrm{Q}^{* *}$ & $\mathrm{~L}^{* *}$ & $\mathrm{~L}^{* *}$ \\
\hline CV & 3,1 & 14,76 & 8,9 & 12,54 & 18,23 & 3,23 & 6,82 & 4,73 & 2,61 \\
\hline
\end{tabular}

ns não significativo pelo teste $\mathrm{F}$.

L e Q significativo pelo teste de regressão linear e quadrática respectivamente.

*, ** Significativo a 0,05 e 0,01 de probabilidade pelo teste $\mathrm{F}$, respectivamente.

Médias seguidas das mesmas letras na coluna não diferem entre si a $5 \%$ e $1 \%$ de probabilidade, pelo teste Tukey.

Fonte: Autor, 2017.

Os resultados permitem inferir que as plantas cultivadas no solo que receberam doses iguais ou acima de $13,2 \mathrm{~m}^{3}$ ha-1 de manipueira apresentaram teor de nitrogênio considerado adequado para cultura da alface (30 a $50 \mathrm{~g} \mathrm{~kg}^{-1}$ ) segundo IPA (2008).

Segundo Ermani et al (2005) esta absorção está relacionado provavelmente a maior fração de argila existente no solo argiloso, no qual foi realizado o experimento que por ter maior riqueza natural de nitrogênio disponível para as plantas garantiu maiores quantidades deste elemento o qual foi prontamente aproveitado pela cultura estudada.

O fósforo é crucial no metabolismo das plantas, desempenhando papel importante na transferência de energia da célula, na respiração e na fotossíntese. A dose $52,8 \mathrm{~m}^{3} \mathrm{ha}^{-1} \mathrm{de}$ manipueira disponibilizou maior acúmulo de $\mathrm{P}$ nas folhas, com concentração de $3,8 \mathrm{~g} \mathrm{~kg}^{-1}$, valor adequado a exigência nutricional da alface, que apresenta nas folhas teor de 3 a $7 \mathrm{~g}$ $\mathrm{Kg}^{-1}$, segundo EMBRAPA (2009).

Os resultados permitem inferir que o fósforo proveniente da manipueira incorporada ao solo foi intensamente absorvido pelas plantas concordando com a afirmação de Dutra et al (2008), pois a cultura apresenta grande resposta à sua aplicação ao solo. 
Os resultados obtidos indicaram que não houve diferença significativa a $5 \%$ de probabilidade pelo teste $\mathrm{F}$ entre as médias que corresponde ao teor de potássio no tecido foliar da alface. (Tabela -2).

Observa-se um aumento no teor de potássio nas folhas de alface, entretanto este aumento não foi considerado significativo e apresentaram-se abaixo dos considerados adequados a cultura 0 que segundo EMBRAPA (2009) corresponde a $50 \mathrm{~g} \mathrm{Kg}^{-1}$.

Segundo Malavolta (1997) o fato do teor de potássio no tecido foliar não ter sido suficiente para elevar os teores de nutrientes considerados adequados a cultura pode estar associada a alta permeabilidade da membrana ao potássio, podendo conduzir à uma considerável saída de potássio da célula. Se a atividade metabólica for suprimida, a retenção de potássio na célula depende principalmente do potencial negativo da mesma. Se esse potencial negativo é diminuído, por exemplo, afeta a respiração, a capacidade de retenção de K é também diminuída. Cheeseman; Hanson (1979), relata que essa diminuição pode estar associada pela atividade da ATPaseno qual ocupa importante papel em baixas concentrações de potássio. Corroborando com este estudo, Saraiva et al (2007) e Inoue et al (2011), constataram que o potássio advindo da manipueira tratada não foi suficiente para manter ou elevar os níveis adequados de potássio no tecido foliar das plantas, pois parte do elemento contido na manipueira é perdido quando se trata o resíduo.

O teor de cálcio no tecido foliar variou entre 10,5 a $16,9 \mathrm{~g} \mathrm{Kg}^{-1}$, na ausência e na presença da maior dose $\left(52,8 \mathrm{~m}^{3} \mathrm{ha}^{-1}\right)$ de manipueira respectivamente, sendo que as planta cultivadas no solo que receberam a maior dose de manipueira apresentaram teor de cálcio considerado adequado para a cultura da alface segundo a EMBRAPA (2009) o que corresponde de 15 a $25 \mathrm{~g}$ $\mathrm{kg}^{-1}$ na planta. Isso se deve à presença de cálcio na água residuária que, consequentemente, ficou retido no solo, influenciando no acúmulo desse íon na planta.

É provável que as quantidades de cálcio existentes no solo $\left(4,5 \mathrm{cmol} \mathrm{dm}^{-3}\right)$ tenham sido suficientes para suprir a necessidade planta, embora a água residuária tenha favorecido a elevação do cálcio na parte aérea da alface.

Ressalta-se que uma das funções do Ca nos vegetais é ser estrutural; por este elemento fazer parte da composição da parede celular (Lamela média), por outro lado, o Ca também é considerado essencial por ter a função de sinalizador secundário no metabolismo vegetal.

Para magnésio, observou-se teores médios na folha de alface de $3,3 \mathrm{~g} \mathrm{Kg}^{-1} \mathrm{e}$ atingindo teores de $7,8 \mathrm{~g} \mathrm{Kg}^{-1}$ (aumento de 57\%).

De acordo com EMBRAPA (2009), os teores de magnésio considerados adequados para a cultura da alface, variam de 4 a $6 \mathrm{~g} \mathrm{~kg}^{-1}$ evidenciando que o aumento das doses de manipueira não prejudicou a absorção de magnésio pelas plantas.

O acréscimo de ferro nas folhas da cultura da alface em relação as doses de manipueira aplicada no solo obteve valor máximo na dose $13,2 \mathrm{~m}^{3}$ ha-1 , derivando-se a equação referente ao período acima, foi estimada a dose de manipueira ideal para o teor de ferro na folha $\left(28,18 \mathrm{~m}^{3} \mathrm{ha}^{-1}\right)$ obtendo $98,79 \mathrm{mg} \mathrm{Kg}^{-1}$ de acúmulo do nutriente.

As plantas cultivadas no solo que receberam doses iguais ou acima de $6,6 \mathrm{~m}^{3} / \mathrm{ha}^{-1}$ apresentaram teor de ferro considerado adequado para a cultura da alface que de acordo com EMBRAPA (2009) representam valores entre 30 e $150 \mathrm{mg} / \mathrm{Kg}$. Verifica-se que a manipueira utilizada neste experimento aumentou o acúmulo do teor de ferro no solo e na cultutura da alface, por tanto as quantidades acumuladas de nutrientes refletem o que a planta necessita, e não o que deveria ser aplicado, uma vez que a eficiência da adubação varia em função de alguns fatores, como tipo de solo, dinâmica do nutriente no solo, condição climática da região e essas quantidade de nutrientes acumuladas na planta fornece informações importantes que podem auxiliar em programas de adubação. 
O teor de zinco na área foliar apresentou tendência semelhante à do potássio, ou seja, quanto maior as doses de manipueira incorporadas ao solo maior também o teor de zinco na planta. Embora tenha ocorrido um aumento de $44,2 \%$ do teor de zinco na planta com a aplicação da maior dose de manipueira, não foi suficiente para elevar os teores de zinco na planta, neste caso é necessário realizar estudos com maiores doses do resíduo.

O zinco está diretamente relacionado à síntese e à conservação de auxinas, hormônios vegetais envolvidos no crescimento da planta e na estrutura e funções das enzimas, dos processos de redução do nitrato a nitrito, síntese de ácido indol acético (AIA), síntese de RNAses e de proteínas (MALAVOLTA; VITTI; OLIVEIRA, 1997). Os teores de zinco não foram considerados adequados segundo a EMBRAPA (2009) na cultura da alface pois os mesmos variam de 30 a 100 $\mathrm{mg} \mathrm{Kg}^{-1}$. É importante ressaltar que o zinco é responsável pelo desenvolvimento e crescimento das espécies vegetais além de ser ativador enzimático. Em planta com deficiência de zinco, as alterações morfológicas ficam evidentes principalmente, nas partes mais jovens, podendo citar como alterações a cloros e internerval de folhas novas e pontos necróticos, o que foi evidenciado em algumas plantas (VITTI; SERRANO, 2008).

Ainda de acordo com os resultados obtidos neste experimento as análises para os teores de $\mathrm{Cu}$ e $\mathrm{Mn}$, na cultura analisada apresentaram valores crescente com as melhores médias apresentadas na dose $52,8 \mathrm{~m}^{3} \mathrm{ha}^{-1}$, obtendo teores satisfatório para cultura de 9 e $45,5 \mathrm{mg} \mathrm{kg}^{-1}$ respectivamente (EMBRAPA, 2009).

Quanto aos teores de Manganês, apenas na maior dose $\left(52,8 \mathrm{~m}^{3} \mathrm{ha}^{-1}\right)$ observa-se maior incremento do teor $\left(45,55 \mathrm{mg} \mathrm{kg}^{-1}\right)$ nas folhas, correspondendo a um aumento de $50,9 \%$ se comparado com controle. Segundo EMBRAPA (2009) o teor de manganês na cultura da alface deve estar entre 30 e $150 \mathrm{mg} \mathrm{Kg}^{-1}$, sendo assim, verifica-se a partir dos dados obtidos, que houve aumento significativo no teor de Manganês encontrado nas plantas cultivadas, e o mesmo foi considerado adequados para a cultura da alface.

\subsection{Impacto da aplicação da manipueira no solo}

O impacto do uso de um resíduo em uma cultura não se observa apenas na planta, o solo recebe esses resíduos e pode modificar suas características agronômicas, sendo necessários assim avaliar o impacto desse uso nas características do solo.

A Tabela 3 mostra a análise de fertilidade dos solos utilizados no cultivo de alface antes da aplicação da manipueira e 10 e 30 dias após a aplicação da manipueira. 
Tabela 3. Análise para fins de fertilidade de amostras de solos* coletado antes e após o término do experimento com cultura da alface submetida a doses crescentes de manipueira.

\begin{tabular}{|c|c|c|c|c|c|c|c|c|c|c|}
\hline \multirow{2}{*}{$\begin{array}{l}\text { Doses } \\
\mathrm{m}^{3} \mathrm{ha}^{-1}\end{array}$} & \multirow[t]{2}{*}{$\mathrm{pH}$} & MO & $\mathbf{K}$ & $\mathrm{Ca}$ & CTC & \multirow{2}{*}{$\begin{array}{l}\mathbf{P} \\
\mathrm{mg} / \mathrm{d} \\
\mathrm{m}^{3}\end{array}$} & $\mathrm{Mg}$ & $\mathrm{Na}$ & $\mathbf{v}$ & \multirow{2}{*}{$\begin{array}{l}\text { PSS } \\
\%\end{array}$} \\
\hline & & $\mathrm{g} / \mathrm{dm}^{3}$ & \multicolumn{3}{|c|}{$\mathrm{cmolc} / \mathrm{dm}^{3}$} & & \multicolumn{2}{|c|}{$\mathrm{mmolc} / \mathrm{dm}^{3}$} & $\%$ & \\
\hline \multicolumn{11}{|c|}{ Antes de do experimento } \\
\hline & 6,3 & 18 & 0,36 & 4,4 & 7,4 & 36 & 16 & 0,1 & 85 & 3,0 \\
\hline \multicolumn{11}{|c|}{10 dias após o experimento } \\
\hline 0 & 6,3 & 20 & 0,19 & 3,0 & 4,9 & 41 & 16 & 0,4 & 84,7 & 3,1 \\
\hline 6,6 & 6,5 & 21,5 & 0,36 & 2,2 & 4,6 & 60 & 18 & 0,5 & 68,7 & 3,6 \\
\hline 13,2 & 6,5 & 19,6 & 0,45 & 1,7 & 4,2 & 83 & 18 & 0,6 & 61,8 & 3,8 \\
\hline 26,4 & 6,6 & 20,9 & 0,51 & 1,5 & 4,0 & 96 & 17 & 0,7 & 65,0 & 5,2 \\
\hline 52,8 & 6,4 & 18,4 & 0,48 & 1,0 & 3,0 & 86 & 13 & 0,6 & 54,0 & 5,0 \\
\hline \multicolumn{11}{|c|}{30 dias após o experimento } \\
\hline 6,6 & 7,1 & 22,1 & 0,20 & 2,5 & 4,7 & 42 & 17 & 0,7 & 85,5 & 5,8 \\
\hline 13,2 & 7,0 & 20,9 & 0,19 & 1,7 & 3,0 & 52 & 18 & 0,6 & 72,6 & 5,1 \\
\hline 26,4 & 6,8 & 23,9 & 0,33 & 1,6 & 4,2 & 80 & 20 & 0,7 & 66,9 & 5,0 \\
\hline 52,8 & 6,7 & 23,9 & 0,44 & 1,2 & 3,8 & 89 & 19 & 0,7 & 61,8 & 5,6 \\
\hline
\end{tabular}

* CTC- Capacidade de troca catiônica; MO-matéria orgânica; P- fósforo; K- Potássio; Mg- Magnésio; Ca- cálcio; Nasódio; V-porcentagem de saturação de bases

Fonte: Autor, 2017.

$\mathrm{O} \mathrm{pH}$ do solo é um dos fatores que mais influencia a disponibilidade de nutrientes às plantas. Valores ótimos de $\mathrm{pH}$ variam entre 6,0 e 6,5. Neste intervalo, ocorre a disponibilidade máxima de macronutrientes, bem como limita-se a disponibilidade máxima dos micronutrientes e se reduz a acidez do solo (MALAVOLTA; VITTI; OLIVEIRA, 1997).

Aos 10 e 30 DAT, ocorreu aumento do pH em função da aplicação de doses de manipueira, se comparado ao solo antes do experimento, sendo que o maior valor, aos 10 DAT, foi 6,6 na dose $26,4 \mathrm{~m}^{3} \mathrm{ha}^{-1}$, equivalendo a um aumento de $4,5 \%$. Aos $30 \mathrm{DAT}$, o maior valor do $\mathrm{pH}$ foi de 7,1 para a dose $6,6 \mathrm{~m}^{3} \mathrm{ha}^{-1}$, equivalendo a um aumento de $11,2 \%$, sendo esta elevação creditada à presença dos cátions contidos na manipueira aplicada ao solo (MÉLO et al., 2005).

Infere-se que a adição de manipueira ao solo contribuiu para o aumento do $\mathrm{pH}$, uma vez que continha alto teor de cátions, principalmente, $\mathrm{Ke} \mathrm{Mg}$, o que propiciou o aumento do $\mathrm{pH}$ do solo. Em relação ao cálcio ocorreu um decréscimo em decorrência do acréscimo de doses de manipueira aos 10 e 30 DAT da planta no solo (Tabela 1). O teor de cálcio no solo aos 10 DAT decresceu de $3,0 \mathrm{cmloc} \mathrm{dm}^{-3}\left(0 \mathrm{~m}^{3} \mathrm{ha}^{-1}\right)$ para $1, \mathrm{cmloc} \mathrm{dm}^{-3}$ na dose $52,8 \mathrm{~m}^{3} \mathrm{ha}^{-1}$. Porém, as plantas não apresentaram sintomas de deficiência deste nutriente.

De acordo com Wadt (1999) este comportamento está relacionado a uma possível competição entre o magnésio, o cálcio e o potássio trocável no solo. Infere-se que os baixos teores de cálcio (Ca) encontrados no solo biofertilizado com a manipueira, provavelmente deve-se aos mesmos estarem sendo lixiviados pelos ácidos orgânicos.

Os resultados obtidos neste estudo quanto aos teores de cálcio, se assemelham aos de Barreto (2013) e Fioreto (1987), quando observaram decréscimo de cálcio no solo em virtude do uso da manipueira. Segundo Malavolta, Vitti e Oliveira (1997) os teores de cálcio trocáveis no solo

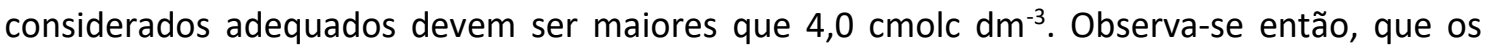
teores ficaram abaixo do índice proposto pelo referido autor em todos tratamentos.

Quanto ao potássio trocável do solo houve tendência semelhante a do fósforo, ou seja, verificase que a aplicação de doses crescentes de manipueira provocou um acréscimo no solo 
independente do tempo de avaliação. Observa-se que houve incremento de potássio disponível de $29,4 \%$ aos 10 DAT em decorrência do aumento das doses de manipueira, uma vez que o teor de tal elemento no referido solo antes do experimento era igual a $0,36 \mathrm{mg} \mathrm{dm}^{-3}$ e $0,51 \mathrm{mg} \mathrm{dm}^{-3}$ para a dose $\left(26,4 \mathrm{~m}^{3} \mathrm{ha}^{-1}\right)$. Entretanto, aos $30 \mathrm{DAT}$, a adição de manipueira provocou o efeito menor, equivalendo a $18 \%$, uma vez que o maior teor de potássio disponível foi de $0,44 \mathrm{mg} \mathrm{dm}^{-}$ ${ }^{3}$ quando se utilizou a maior dose do resíduo $\left(52,8 \mathrm{~m}^{3} \mathrm{ha}^{-1}\right)$.

$\mathrm{O}$ alto teor de potássio existente na manipueira possivelmente tenha sido responsável pelo acréscimo do cátion no solo. De acordo com Malavolta, Vitti e Oliveira (1997), teores de potássio trocável no solo acima de $0,2 \mathrm{cmol} \mathrm{dm}^{-3}$ são considerados adequados, evidenciando que a manipueira utilizada neste experimento serviu como fonte de adubação potássio, uma vez que o solo utilizado neste experimento antes da aplicação da manipueira se encontrava com o teor de $0,36 \mathrm{cmol} \mathrm{dm}^{-3}$ e após a dose $26,2 \mathrm{~m}^{3}$ ha-1 aplicada no solo alcançou um teor $0,51 \mathrm{cmol}$ $\mathrm{dm}^{-3}$, confirmando a hipótese de que o potássio contido em tal resíduo foi suficiente para elevar os teores desse cátion no solo e atender a demanda da cultura durante o experimento, mesmo com o decréscimo aos 30DAT. Acredita-se que esta redução aos 30 DAT esteja associada a absorção pelas plantas ao longo de seu desenvolvimento pois o potássio é o nutriente mais exigido pelas hortaliças.

$O$ teor de fósforo no solo foi considerado adequado em relação ao recomendado pela EMBRAPA (2009) aos 20 e 30 DAT. Observa-se que houve incremento de fósforo disponível de $62,5 \%$ aos 10 DAT em decorrência do aumento das doses de manipueira, uma vez que o teor de tal elemento no referido solo antes do experimento era igual a $36 \mathrm{mg} \mathrm{dm}^{-3}$ e $96 \mathrm{mg} \mathrm{dm}^{-3}$ para a dose $\left(26,4 \mathrm{~m}^{3} \mathrm{ha}^{-1}\right)$. Entretanto, aos $30 \mathrm{DAT}$, a adição de manipueira provocou o efeito menor, equivalendo a $59 \%$, uma vez que o maior teor de fósforo disponível foi de $89 \mathrm{mg} \mathrm{dm}^{-3}$ quando se utilizou a maior dose do resíduo $\left(52,8 \mathrm{~m}^{3} \mathrm{ha}^{-1}\right)$.

Apesar do acréscimo de fósforo no solo ter sido menor aos 30 DAT, foi suficiente para elevar os teores de nutrientes considerado adequado por Malavolta; Vitti; Oliveira (1997), os quais variam de 31 a $90 \mathrm{mg} \mathrm{dm}^{-3}$.

Segundo Vanraj (1991) esta redução aos 30 DAT pode estar associada a lixiviação e pode estar associado também a baixa mobilidade pois a absorção do fósforo pode ficar comprometida em solos compactados devido ao fato da resistência mecânica do solo reduzir a habilidade de absorção específica.

Os resultados obtidos mostraram que, com a manipueira, ocorreu um aumento médio de $16,2 \%$ nos teores de matéria orgânica do solo aos 10 e 30 DAT para a dose $26,4 \mathrm{~m}^{3} \mathrm{ha}^{-1}$ se comparados com a análise inicial do mesmo solo. Este aumento da matéria orgânica considerado adequado por Freitas et al (2012) é fundamental para a manutenção do micro e da mesobiota do solo, pois a ação dos decompositores sobre essa matéria vai devolver ao solo os nutrientes necessários para que os seres vivos que habitam o solo possam adquirir energia para sobreviver e também para manter o equilíbrio e a conservação do solo.

Os dados expostos na (Tabela 3) mostram que ocorreu aumento positivo em relação ao sódio decorrente da incorporação de doses crescentes de manipueira aos 10 e 30 DAT, sendo que correu um aumento de $85,7 \%$ de sódio trocável quando comparado ao solo antes do experimento na dose $26,4 \mathrm{~m}^{3} \mathrm{ha}^{-1}\left(0,7 \mathrm{mmolc} \mathrm{dm}^{-3}\right)$

Ferreira et al (2007) e Dutra et al (2008) relatam que elevadas concentrações de sódio no solo podem acarretar estresse hídrico, salino, desequilíbrio nutricional e toxicidade a cultura.

A aplicação da manipueira não chegou a salinizar ou sodificar o solo, uma vez que o pH foi menor que 8,5 em todos tratamentos e a percentagem do sódio trocável (PST) do solo foi menor que $15 \%$ para todos as doses, conforme classificação proposta por Richards (1994), assim é oportuno 
salientar que o uso da manipueira deve ser feito de maneira criteriosa visto que pode haver, a longo prazo, salinização e / ou sodificação do solo devido ao uso do resíduo como fertilizante. O teor de cálcio não obteve acréscimo para o solo quando se utilizou o efluente. De modo geral, percebe-se que a dose $26,4 \mathrm{~m}^{3}$ ha-1apresentou as maiores concentrações em todos os parâmetros, demonstrando que a manipueira aumentou os atributos químicos do solo e foi absorvida pela cultura.

O uso da manipueira como biofertilizante se mostra promissor e importante do ponto de vista ambiental e as principais características de sua aplicação no crescimento de alface, teor de nutrientes nas plantas e no solo após aplicação estão listadas na Tabela 4.

Tabela 4. Principais características observadas na aplicação da manipueira no crescimento da alface, teores de nutrientes e solos após aplicação.

\begin{tabular}{l} 
Crescimento de alface \\
\hline \multicolumn{1}{c}{ Teores de nutrientes }
\end{tabular}

\section{CONCLUSÃO}

O efeito da aplicação da manipueira no crescimento da alface se mostrou mais eficiente para as dose $26,4 \mathrm{~m}^{3}$ há $^{-1}$. A dose $6,6 \mathrm{~m}^{3} \mathrm{ha}^{-1}$ propiciou maior ganho de massa fresca e massa seca da parte aérea, enquanto a dose $26,4 \mathrm{~m}^{3}$ ha-1 proporcionou incremento significativo nos demais parâmetros de crescimento avaliados. Quando aplicadas em doses adequadas, a manipueira oferece muitas vantagens no crescimento e desenvolvimento da cultura da alface, sendo dessa forma, benéfica aos agricultores pelo baixo custo e pela responsabilidade ambiental obtida com sua reutilização. Os teores de nutrientes determinados nas plantas após o cultivo com manipueira, mostraram que este resíduo atuaria de forma mais eficiente como um complemento aos fertilizantes já utilizados, uma vez que, mesmo na maior dose utilizada neste estudo, os teores de alguns nutrientes não atingiram os níveis adequados na planta e doses superiores, se aplicadas demonstrariam efeitos deletérios no crescimento da alface. $\mathrm{Na}$ avaliação do impacto da aplicação da manipueira no solo, notou-se que a incorporação da manipueira promoveu elevação do $\mathrm{pH}$, da matéria orgânica e dos teores de fósforo, potássio, magnésio e sódio trocáveis no solo estudado, e baixo incremento de CTC e teor de Ca. O uso de manipueira como fonte de adubação poderá levar a salinização do solo em cultivos posteriores, entre tanto, no período do cultivo deste experimento o uso deste efluente não provocou salinização ou sodificação do solo em estudo. Podendo-se inferir que a aplicação da manipueira nas quantidades utilizadas nesse estudo não impactariam ambientalmente podendo ser uma forma de reutilização e minimização dos descartes desse efluente. 


\section{REFERÊNCIAS BIBLIOGRÁFICAS}

ARAÚJO NETO, S. E. de; CAMPOS, P. A. et al. Organic polyculture of passion fruit, pineapple, corn and cassava: the influence of green manure and distance between espaliers. Ciência \& Agrotecnologia, v. 38, n. 3, p.247-255, 2014.

CARDOSO, E. Uso de manipueira como biofertilizante no cultivo do milho: avaliação no efeito do solo, nas águas subterrâneas e na produtividade do milho. 2005. Dissertação de Mestrado. UESC, Criciúma, SC.

CHARRIAU, A., LESVEN, L. et al. Standard methods for the examination of water and waste-water. Nova York: Amer Public Health Assn, 2005, 476p.

CHEESEMAN, H. Utilização da manipueira para produção de biomassa. In: CEREDA, M. P (coord): Manejo, Uso e Tratamento de Subprodutos da Industrialização da Mandioca. Fundação Cargill, v.4, p.117-185, 1979.

DAMASCENO, S.; CEREDA, M. P. et al. Production of volatile compounds by Geotrichum fragans using cassava wastewater as substrate. Process Biochemistry, v.39, p.411-414, 2003.

DUARTE, A. S.; ROLIM, M. M. et al. Alterações dos atributos físicos e químicos de um neossolo após aplicação de doses de manipueira. Rev. Bras. Engenharia Agrícola e Ambiental., v. 17, n. 9, p.938-946, 2013.

DUTRA, A. T. B ; SILVA, E. N. et al. Acúmulo de íons e crescimento de pinhão-manso sob diferentes níveis de salinidade. Revista Ciência Agronômica, v.40, n.2, p.240-246, 2008

EMBRAPA. Comunicado técnico 179. $1^{\circ}$ ed. 2011. 6 p.

ERNANI, P. R.; SANGOI, L. et al. A forma de aplicação da uréia e dos resíduos vegetais afeta a disponibilidade de nitrogênio. Ciência Rural, v.35, p.360-365, 2005.

FEFERREIRA, P. A.; GARCIA, G. O. et al. Produção relativa do milho e teores folheares de nitrogênio, fósforo, enxofre e cloro em função da salinidade do solo. Revista Ciência Agronômica, v.38, n.1, p.7-16, 2007.

FREITAS, D. A. F.; SILVA, M. L. N. et al. Índices de qualidade do solo sob diferentes sistemas de uso e manejo florestal e cerrado nativo adjacente. Revista Ciência Agronômica, v. 43, n. 3, p. 417-428, 2012.

INOUE, K. R. A. et al. Concentração de nutrientes em plantas de milho adubadas e biofertilizantes obtidos na digestão anaeróbia da manipueira. Engenharia na Agricultura, v.19, p.236-243, 2011.

IPA - Instituto Agronômico de Pernambuco. Recomendações de adubação para o Estado de Pernambuco. Recife: IPA, 2008. 64p.

MAGALHÃES, A. et al. Desenvolvimento inicial do milho submetido à adubação com manipueira. Ver. Bras. Engenharia Agrícola e Ambiental, v.18, n.7, p.675-681, 2014.

MALAVOLTA, E.; VITTI, G. C.; OLIVEIRA, S. A. Avaliação do estado nutricional das plantas: princípios e aplicações. 2. ed. Piracicaba: Potafós, 1997. 319 p.

MÉLO, R. F. et al. Alterações físicas e químicas em três solos tratados com água residuária de mandioca. Irriga, v. 10, n. 4, p. 383-392, 2005.

MÉLO, R. F. et al. Deslocamento miscível de cátions básicos provenientes da água residuária de mandioca em colunas de solo. Rev. Bras. Engenharia Agrícola e Ambiental, v.10, n.2, p.456-465, 2009.

NEVES, P. A. P. F. G.; PAULA, M. T. et al. Determinação de Metais em Espécies Florestais da Amazônia. Rev. Virtual Quim., v. 8, n. 5, p. 1404-1420, 2016.

RESENDE, G.M.; ALVARENGA, M.A.R. et al. Rendimento e teores de macronutrientes em alface tipo americana em função de doses de nitrogênio e molibdênio em cultivo de verão. Ciência e Agrotecnologia, v. 33, p. 153-163, 2009. 
RICHADS, J.; BI, I.A.Z. Effect of sowing density and seedbed type on yield and yield components in Bambara Groundnut (Vigna Subterranea) in woodland savannas of Cote D'ivoire. Experimental Agriculture, v.46, p.99-110, 1994.

SALVADOR, M. A.; JOSÉ, J. V; REZENDE, R. et al. A aplicação de efluente líquido de fecularia em substratos e solos para produção de mudas de eucalipto. Revista em Agronegócios e Meio Ambiente, v.5, p.175-188, 2012.

SARAIVA, F. Z. et al. Uso de manipueira no desenvolvimento vegetativo do milho em ambiente protegido. Rev. Bras. Engenharia Agrícola e Ambiental, v.11, p.30-36, 2007.

SEVERINO, L. S.; CARDOSO, G. D. et al. Método para determinação da área foliar da mamomeira. Revista Brasileira de oleaginosas e fibrosas, v. 8, n. 1, p. 753-762, 2004.

SILVA, F. F.; FREITAS, P. S. L. et al. Impacto da aplicação de efluente maturado de fecularia de mandioca em solo e na cultura do sorgo. Acta Scientiarum Agronomy, v. 26, p. 421-427, 2004.

SOUZA, D. M. G; MIRANDA, L. N. et al. Acidez do solo e sua correção. In: Novais, R.F..; AALVAREZ, V.; BARROS, N.F.; FONTES, R.L.F.; CANTARUTTI, R.B.; NEVES, J. C.L.; Fertilidade do solo. Viçosa:SBCS, 2007, p.205-275.

SOUZA, S. O.; OLIVEIRA, L. C. et al. Cyanogenic Residues: Environmental Impacts, Complexation with Humic Substances, and Possible Application as Biofertilizer. Water Air Soil Pollut., v. 225, p.2223-2230, 2014.

VANRAJ, A. Tree pruning mulch increases soil $\mathrm{C}$ and $\mathrm{N}$ in a shaded coffee agroecosystem in Hawaii. Soil Biology and Biochemistry, v.41, p.2527-2534, 1991.

VITTI, C. G.; SERRANO, de E. G. C. O Zinco na agricultura. Revista DBO Agrotecnologia, v.15, p.121-138, 2008.

ZIECH, A.R.D.; CONCEIÇÃO, P.C. et al. Cultivo de alface em diferentes manejos de cobertura do solo e fontes de adubação. Rev. Bras. Engenharia Agrícola e Ambiental, v.18, n.9, p.948-954, 2014.

ZOBIOLE, L. H. S.; CASTRO, C. et al. Curva de cescimento, estado nutricional, teor de óleo e produtividade de girassol hibrido BRS 191 cultivado no estado do Paraná. Revista Brasileira de Oleaginosas e Fibrosas, v. 14, p.55-62, 2010. 